\title{
Evidence-based indicators for the measurement of quality of primary care using health insurance claims data in Switzerland: results of a pragmatic consensus process
}

Eva Blozik ${ }^{1,2,3^{*}}$ (D, Oliver Reich ${ }^{1}$, Roland Rapold ${ }^{1}$, Martin Scherer ${ }^{2}$ and Swiss Quality Indicator for Primary Care (SQIPRICA) Working Group

\begin{abstract}
Background: The level of quality of care of ambulatory services in Switzerland is almost completely unknown. By adapting existing instruments to the Swiss national context, the present project aimed to define quality indicators (Ql) for the measurement of quality of primary care for use on health insurance claims data. These data are preexisting and available nationwide which provides an excellent opportunity for their use in the context of health care quality assurance.

Methods: Pragmatic 6-step process based on informal consensus. Potential QI consisted of recommendations extracted from internationally accepted medical practice guidelines and pre-existing Ql for primary care. An independent interdisciplinary group of experts rated potential QI based on explicit criteria related to evidence, relevance for Swiss public health, and controllability in the Swiss primary care context. Feasibility of a preliminary set of QI was tested using claims data of persons with basic mandatory health insurance with insurance at one of the largest Swiss health insurers. This test built the basis for expert consensus on the final set of QI.

Results: Of 49 potential indicators, 23 were selected for feasibility testing based on claims data. The expert group consented a final set of $24 \mathrm{QI}$ covering the domains general aspects/ efficiency (7 QI), drug safety (2), geriatric care (4), respiratory disease (2), diabetes (5) and cardiovascular disease (4).

Conclusions: The present project provides the first nationwide applicable explicit evidence-based criteria to measure quality of care of ambulatory primary care in Switzerland. The set intends to increase transparency related to quality and variance of care in Switzerland.
\end{abstract}

Keywords: Quality indicator, Quality assessment, Quality measurement, Claims data, Health insurance, Evidence-based, Consensus process

\footnotetext{
* Correspondence: eva.blozik@helsana.ch

${ }^{1}$ Department of Health Sciences, Helsana Group, P.O. Box, Zürich, Switzerland

${ }^{2}$ Department of General Practice/Primary Care, University Medical Center

Hamburg-Eppendorf, Hamburg, Germany

Full list of author information is available at the end of the article
}

(c) The Author(s). 2018 Open Access This article is distributed under the terms of the Creative Commons Attribution 4.0 International License (http://creativecommons.org/licenses/by/4.0/), which permits unrestricted use, distribution, and reproduction in any medium, provided you give appropriate credit to the original author(s) and the source, provide a link to the Creative Commons license, and indicate if changes were made. The Creative Commons Public Domain Dedication waiver (http://creativecommons.org/publicdomain/zero/1.0/) applies to the data made available in this article, unless otherwise stated. 


\section{Background}

A broad spectrum of initiatives aim to increase the quality of primary care in Switzerland [1-3]. These initiatives include a variety of different approaches such as certification measures [4-6], in-house medical guideline development or quality circles [7] that vary in terms of regional spread, objectives, target population, and evidence basis. Despite this wide range of projects, the level of quality of care of ambulatory services in Switzerland is almost completely unknown [8]. This is especially paradoxical, as the Swiss health insurance act (Art. 22a Krankenversicherungsgesetz) requires the collection of quality information in the context of Swiss basic mandatory health insurance. Since several years, the Swiss Federal Office of Public Health is working on strategies to realise these requirements, which are practically disregarded within the current collective tariff agreements such as TARMED, the tariff system of ambulatory medical procedures in Switzerland [9]. However, results or at least initiatives addressing this issue are still lacking. Therefore, the topic of developing defined and feasible approaches for national quality assurance in ambulatory care are of great political and practical relevance.

According to the Institute of Medicine (IOM) report, To Err Is Human, most errors in health care result from inefficient and variable processes, changing case mix of patients, inconsistencies in health service reimbursement systems, differences in provider education and experience, and numerous other factors [10]. However, quality improvement is not possible without quality measurement [11].

Quality indicators (QI) are measurable items designed to assess, compare, and improve quality of health services [12]. So far, there are no QI for measurement of quality of care of primary care outpatient services established for application within the Swiss healthcare setting, despite some small certification programs, on a voluntary basis.

Although there are well-known limitations, health insurance claims data of mandatory basic health insurance provide a valuable opportunity for their use in the context of health care quality assurance. These real world data are pre-existing, nationwide available, and they link information on individual patients with information on healthcare providers, settings and health plans. Therefore, they allow for both cross-sectional and longitudinal evaluations on different levels from the individual patient to the system level.

As Switzerland is lagging behind other European countries with respect to quality measurement in the ambulatory sector [13-16], the present project aims to define a set of evidence-based QI for the measurement of quality of primary care $[17,18]$. To increase applicability without the barrier of huge preceding investments the QI are intended to be used on Swiss health insurance claims data. The present study responds to political discussions about how to increase transparency related to quality of ambulatory care in Switzerland by pragmatically combining pre-existing evidence-based methods with local expertise.

\section{Methods \\ Context of the study}

Health insurance is mandatory for all persons residing in Switzerland. The basic health insurance package is the same in the entire country and includes all outpatient or hospital medical treatments deemed appropriate, medically effective, and cost-effective. Supplementary hospital insurance in Switzerland can be purchased, if individuals wish further comfort of a semiprivate or private ward or treatment in another canton for personal reasons. There are about 60 insurance companies providing basic health coverage in Switzerland, and they offer a range of different premiums and health plans from which Swiss residents are free to choose [19]. Registering with a GP is generally not required, and residents insured in the standard insurance plan have free choice among mostly self-employed GPs. However, persons are free to enrol in managed care plans (e.g. integrated care plans, telephone triage plans, capitated and non-capitated plans) in which they need to contact a specific primary care provider before seeking care with other healthcare providers. In 2016, there were 0,95 generalist physicians per 1000 inhabitants in the ambulatory sector [20]. Primary (and specialist) care tends to be physician-centered, with nurses and other health professionals playing a relatively small role [21]. The present project is an initiative of the health services research department of Helsana Group. Helsana is one of the largest Swiss health insurances covering about $15 \%$ of the Swiss population from all parts of the country.

\section{Study protocol}

The process of defining suitable QI consisted of several steps (Fig. 1). In Switzerland, there is no formal or national process or institution responsible for summarizing and operationalization of evidence for quality improvement purposes. National guidelines for primary care in Switzerland are lacking. However, the Swiss and the German health system have many structural similarities such as the existence of a social health insurance system, the public/ private mix of health service providers, the choice between various competing health insurances, and financing of health care costs by premiums, public funds, and co-payments. Moreover, there are no linguistic barriers as both countries are part of the German-speaking area. Therefore, the present project based on recommendations from guidelines of the German association of primary care and family medicine (Deutsche Gesellschaft für Allgemeinmedizin und Familienmedizin, DEGAM) and the German National 


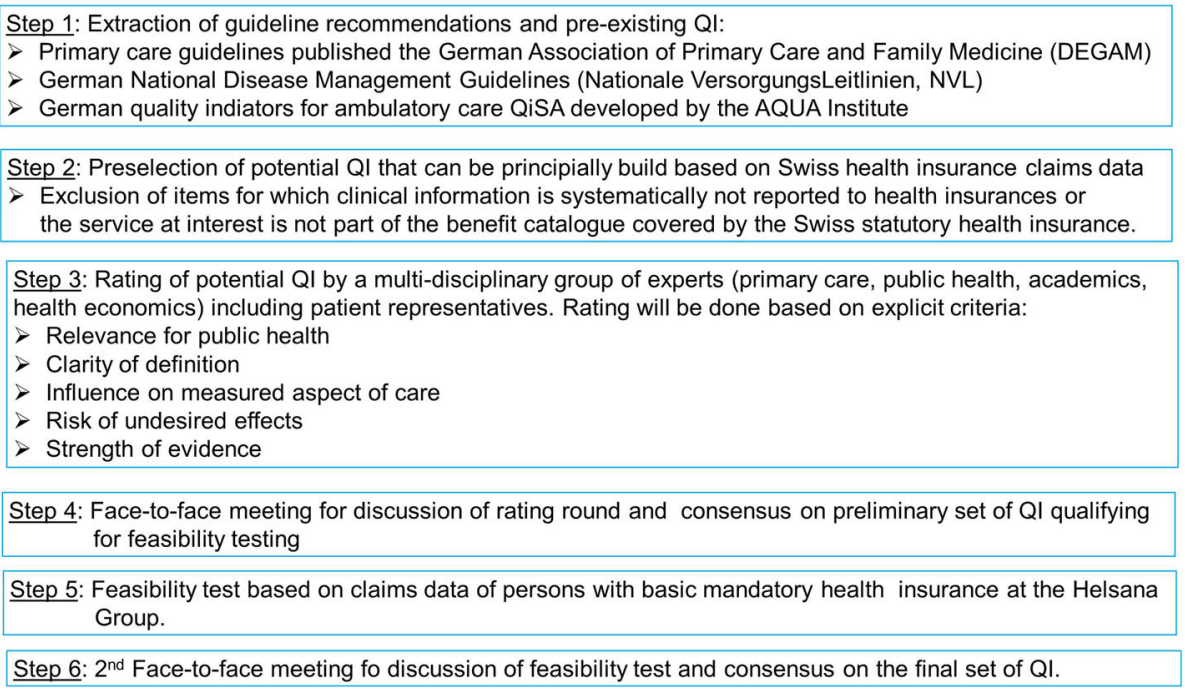

Fig. 1 Study protocol

Disease Management Guidelines (Nationale VersorgungsLeitlinien, NVL) and on QISA (QI for primary care, developed by the AQUA Institute) indicators. Development of guidelines or QI followed an established clearly defined and internationally acknowledged methodology [22-24].

In a first step, we extracted all recommendations for or against specific medical interventions of all currently existing DEGAM and NVL guidelines and all QISA. Not all recommendations and QI extracted can be constructed using the information that is available in health insurance claims. Therefore, in a second step, this list of potentially eligible items for QI was checked for operationalisability on Swiss health insurance claims data. In a third step, a multidisciplinary group of 9 independent experts (Swiss Quality Indicator for Primary Care (SQIPRICA) Working Group) from primary care, public health, and health economics including patient and consumer representatives rated the list of potential QI. Criteria for rating were relevance for public health, clarity of definition, influence on measured aspect of care, risk of undesired effects, and strength of evidence. The rating process was derived from the methodology used for development of QI in the context of national disease management guidelines in Germany [22]. Influenceability was defined as the potential of a GP to modify care. For example, interventions generally done in the hospital setting were considered to be not influenceable. Experts were asked to rate the potential indicators according to a 4 point Likert scale $(1=$ incorrect; 2 =rather incorrect; 3 = rather correct; $4=$ fully correct). For the aspect risk of undesired effects, they were asked to answer yes or no. The aim of including the expert group was to ensure that the resulting QI were calculable, relevant, and influenceable by primary care within the Swiss healthcare system.

As a fourth step, there was a face-to face-meeting of the project team and the expert group. The objective of that workshop was to discuss discrepant rating results and principal difficulties, to converse the strengths and limitations of claims data in this context, and to reach consensus on a preliminary set of QI qualifying for a first practical test. For preparation of the workshop, the experts received a descriptive analysis of the rating results (mean, median, range of Likert scale ratings) for each candidate QI by criterion (i.e. relevance for public health, clarity of definition, influence on measured aspect of care, risk of undesired effects, and strength of evidence). We did not apply any cut-points for exclusion based on Likert score rating results. Therefore, the rating results of all potential indicators included in step 3 were made visible to the expert group members and were used as a basis for discussion in the group.

The fifth step was a feasibility test. This was done using claims data of 950'000 adult persons with basic mandatory health insurance in the year 2013. The patient-level database included information on socio-demographics, health insurance status, prescribed drugs, health care utilization and its associated costs as well as hospital discharge information and the date of death. In this sample, the proportion of persons presenting with the QI at interest was calculated, stratified by socio-demographic (age class, sex, resident in French or Italian speaking canton, amount of individually eligible annual deductible, voluntary choice of a managed care health plan) and clinical (cancer, cardiovascular disease, psychological disorders as measured using pharmaceutical cost 
groups (PCG)) characteristics [25]. Inefficient me-too medications were operationalized based on the list published by Fricke \& Klaus [26]. Potentially Inappropriate Medication (PIM) are pharmaceuticals associated with an increased risk for adverse drug reactions in older persons that should be avoided whenever possible, according to expert consensus. PIM were defined based on the Beers criteria and the PRISCUS list $[27,28]$. Each active agent and combinations from these lists were attributed to one or more ATC Anatomical Therapeutic Chemical Classification System (ATC) codes [29]. The definition of PIM variables accounted for the fact that certain medications were considered inappropriate only above a certain dose or for long-term use. Analyses were performed using the statistical package $\mathrm{R}$, version 3.2.0 ( $\mathrm{R}$ Foundation for Statistical Computing, Vienna, Austria).

As a final (sixth) step a second workshop with the expert group was performed to discuss the results of the feasibility test, to receive recommendations for adaptation and to reach consensus about the final set of QI.

\section{Ethical approval}

The analysis complied with the Swiss Federal Law on data protection. All data were anonymized and de-identified prior to the performed analysis to protect the privacy of patients, physicians, and hospitals. According to the national ethical and legal regulation, an ethical approval was not needed because the data were retrospective, pre-existing, and de-identified. Since data was anonymized, no consent of patients was required.

\section{Results}

We extracted guideline recommendations and QI from 12 National Disease Management Guidelines, 12 QiSA indicator sets and 8 DEGAM primary care $\mathrm{S} 3$ guidelines.

We excluded duplicates, services that are not part of the basic mandatory health insurance package in Switzerland and measures that cannot be mapped using claims data such as details of clinical processes, decision making, or communication that are not relevant for reimbursement. A list of 49 potential QI was sent to the expert group for rating of relevance for public health, clarity of definition, influence on measured aspect of care, risk of undesired effects, and strength of evidence. Overall, there were few discrepancies related to the rating across the group. All potential QI were assigned high values for the aspect "relevance for public health" (mean and median 3 = "rather correct").

Table 1 lists those indicators that were - according to expert consensus - rated inadequate for use as a QI in the Swiss healthcare setting and were therefore excluded. Reasons for exclusion were the indicator not being influenceable by primary health care providers, being irrelevant for Swiss primary healthcare due to medical practice, medication market or patient population, or the indicator not being calculable due to lack of clinical information in health insurance claims data. These concerns were reflected in consistently low Likert scores for "influence on measured aspect of care" and "risk of undesired effects" for all those potential QI listed in Table 1. The workshop resulted in a set of 23 preliminary indicators qualifying for the feasibility test covering the domains general aspects/ efficiency (7 QI), drug safety (2), geriatric care (4), respiratory disease (3), diabetes (4) and cardiovascular disease (3).

The results of the feasibility test were discussed in a second face-to face meeting of the project team and the expert group. According to the experts assessment, the feasibility test revealed that it was possible to operationalize all preliminary indicators, and all indicators were sensitive to age, gender, PCG, and to characteristics of health insurance. However, based on discussion related to actual public health needs, applicability and influenceability, the expert committee decided to modify the preliminary set as follows: 1 asthma indicator was dropped because of limited control of primary care physician. The definition and number of indicators related to diabetes mellitus were made more consistent with recent Swiss real-life evidence [30-32]. In addition, the indicators relating to care for patients with cardiovascular disease were made more specific by investigating therapy with statins and ASS separately in two different patient subgroups (i.e. patients after myocardial infarction and patients after stroke). Based on informal consensus, the experts passed a final set of 24 QI including 7 QI measuring general aspects/ efficiency, 2 QI assessing drug safety, 4 QI related to geriatric care, and 11 QI measuring the management of highly prevalent chronic diseases ( 2 respiratory disease, 5 diabetes mellitus, 4 cardiovascular disease) (Table 2).

\section{Discussion}

The present project provides the first evidence-based nationwide measures for quality of primary ambulatory care in Switzerland applicable on pre-existing data. The consensus process resulted in 24 indicators that are - in principle - ready for use in a broad variety of contexts. For example, 4 indicators for quality care of diabetes patients have been recently included in pay-for-performance (P4P) contracts between networks of primary care physicians and a Swiss health insurance [33]. On a higher level, the proposed QI help to increase transparency related to the level of and awareness for variance of quality of primary care in Switzerland. In addition, they may build the basis for quality assurance projects of health service providers. Therefore, such indicators may also be helpful for decision making of all stakeholders in the Swiss health system.

Recently, Ebert et al. published the Swiss Primary Care Active Monitoring (SPAM) instrument consisting of 56 indicators related to the organization of primary care in Switzerland. SPAM tool aims to support a better 
Table 1 Results of the first workshop: rated inappropriate for use as a QI in the Swiss healthcare setting

\begin{tabular}{|c|c|c|}
\hline Category & Potential indicator & Reason \\
\hline General aspects, efficiency & $\begin{array}{l}\text { Proportion of patients enrolled in health plans per } \\
\text { region }\end{array}$ & Not related to quality of primary care \\
\hline General aspects, efficiency & $\begin{array}{l}\text { Proportion of hospitalisations for interventions that } \\
\text { can be adequately done in the ambulatory setting }\end{array}$ & Measures quality of hospital care/ hospital processes \\
\hline General aspects, efficiency & Number of hospitalisations per 1000 persons & $\begin{array}{l}\text { Rather a measure of hospital processes, and density } \\
\text { parameters than of primary care }\end{array}$ \\
\hline General aspects, efficiency & Proportion of patients receiving medication therapy & $\begin{array}{l}\text { No clear indicator of quality. Not specific to primary } \\
\text { care. }\end{array}$ \\
\hline General aspects, efficiency & $\begin{array}{l}\text { Share of prescriptions of new me-too medications } \\
\text { of the total market }\end{array}$ & $\begin{array}{l}\text { A current classification of me-too medications is not } \\
\text { available for Switzerland }\end{array}$ \\
\hline Respiratory disease & $\begin{array}{l}\text { Proportion of patients with asthma or COPD receiving } \\
\text { combinations of reproterol \& cromoglicinic acid }\end{array}$ & $\begin{array}{l}\text { reproterol and cromoglicinic acid are not on the Swiss } \\
\text { market/ use is very unusual }\end{array}$ \\
\hline Respiratory disease & $\begin{array}{l}\text { Proportion of patients with asthma or COPD receiving, } \\
\text { die } \mathrm{N} \text {-acetylcystein, ambroxol or myrtol for elimination } \\
\text { of secret }\end{array}$ & $\begin{array}{l}\text { Medications are not on the Swiss market/ use is very } \\
\text { unusual }\end{array}$ \\
\hline Respiratory disease & $\begin{array}{l}\text { Proportion of patients with COPD receiving } \\
\text { pneumococcal vaccination }\end{array}$ & $\begin{array}{l}\text { Asthma and COPD cannot be differentiated in the claims } \\
\text { dataset because ambulatory diagnoses are lacking }\end{array}$ \\
\hline Respiratory disease & $\begin{array}{l}\text { Proportion of pregnant women with incident therapy } \\
\text { with leukotriene receptor antagonists }\end{array}$ & $\begin{array}{l}\text { Relatively small number of cases, therefore not suitable } \\
\text { for large scale measurement }\end{array}$ \\
\hline Respiratory disease & $\begin{array}{l}\text { Proportion of pregnant women with incident specific i } \\
\text { mmunotherapy }\end{array}$ & $\begin{array}{l}\text { Relatively small number of cases, therefore not suitable } \\
\text { for large scale measurement }\end{array}$ \\
\hline Respiratory disease & $\begin{array}{l}\text { Proportion of children/ teenagers with asthma receiving } \\
\text { oral beta-2-sympathomimetics in acute situations }\end{array}$ & Clinial information is missing \\
\hline Respiratory disease & $\begin{array}{l}\text { Proportion of patients with asthma receiving inhalative } \\
\text { medication }\end{array}$ & $\begin{array}{l}\text { Identification of patients is based on medication. } \\
\text { Therefore, no meaningful interpretation of results possible. }\end{array}$ \\
\hline Respiratory disease & $\begin{array}{l}\text { Proportion of patients with asthma with long term } \\
\text { inhalative corticosteroids }\end{array}$ & $\begin{array}{l}\text { Asthma and COPD cannot be distinguished using claims } \\
\text { data. } \\
\text { Identification of patients is based on medication. } \\
\text { Therefore, no meaningful interpretation of results possible. }\end{array}$ \\
\hline Cardiovascular disease & $\begin{array}{l}\text { Proportion of patients with heart failure receiving } \\
\text { laboratory control of electrolytes and renal function } \\
\text { semi-yearly }\end{array}$ & $\begin{array}{l}\text { Population cannot be determined because ambulatory } \\
\text { diagnoses are lacking in Swiss health insurance claims }\end{array}$ \\
\hline Cardiovascular disease & $\begin{array}{l}\text { Proportion of patients after coronary stent implant } \\
\text { receiving triple therapy } \\
\text { (ASS + Clopidogrel + Anticoagulation) }\end{array}$ & $\begin{array}{l}\text { Measures quality of care of cardiologists/ interventional } \\
\text { cardiologists (as opposed to primary care) }\end{array}$ \\
\hline Cardiovascular disease & $\begin{array}{l}\text { Proportion of patients after aortocoronary Bypass / } \\
\text { acute coronary syndrome and Anticoagulation only }\end{array}$ & $\begin{array}{l}\text { Measures quality of care of cardiologists/ interventional } \\
\text { cardiologists (as opposed to primary care) } \\
\text { Measures quality of hospital care }\end{array}$ \\
\hline Cardiovascular disease & $\begin{array}{l}\text { Proportion of patients after coronary bypass receiving } \\
\text { multidisciplinary rehabilitation }\end{array}$ & $\begin{array}{l}\text { No coherent way of accounting of rehabilitation services } \\
\text { in Switzerland, no information about multidisciplinarity }\end{array}$ \\
\hline Cardiovascular disease & $\begin{array}{l}\text { Proportion of ambulatory patients with laboratory test } \\
\text { for BNP und NT-proBNP }\end{array}$ & Recommendation is not clear enough. \\
\hline Depression & $\begin{array}{l}\text { Proportion of patients resistant to depression treatment } \\
\text { receiving augmentation of antidepressants with } \\
\text { carbamazepine, lamotrigine, pindolol, valproate, } \\
\text { dopamine agonists, psychostimulants, thyroid } \\
\text { hormone or other hormones }\end{array}$ & Clinical information is missing \\
\hline Diabetes mellitus & $\begin{array}{l}\text { Proportion of patients with pain in diabetic neuropathy } \\
\text { treated with traditional nonsteroidal antiphlogistics }\end{array}$ & Clinical information is missing \\
\hline Diabetes mellitus & $\begin{array}{l}\text { Proportion of patients with pain in diabetic neuropathy } \\
\text { treated with selective Cox-2 inhibitors }\end{array}$ & Clinical information is missing \\
\hline
\end{tabular}

understanding of the Swiss PC system's performance and effectiveness on a meta level [34]. It addresses collaboration and coordination of stakeholders, access, and supply of services and care providers. But does not focus on quality in various clinical situations as our indicators do. Thus, most SPAM aspects are not included in reimbursement information and can thus not be measured based on health insurance claims data. 


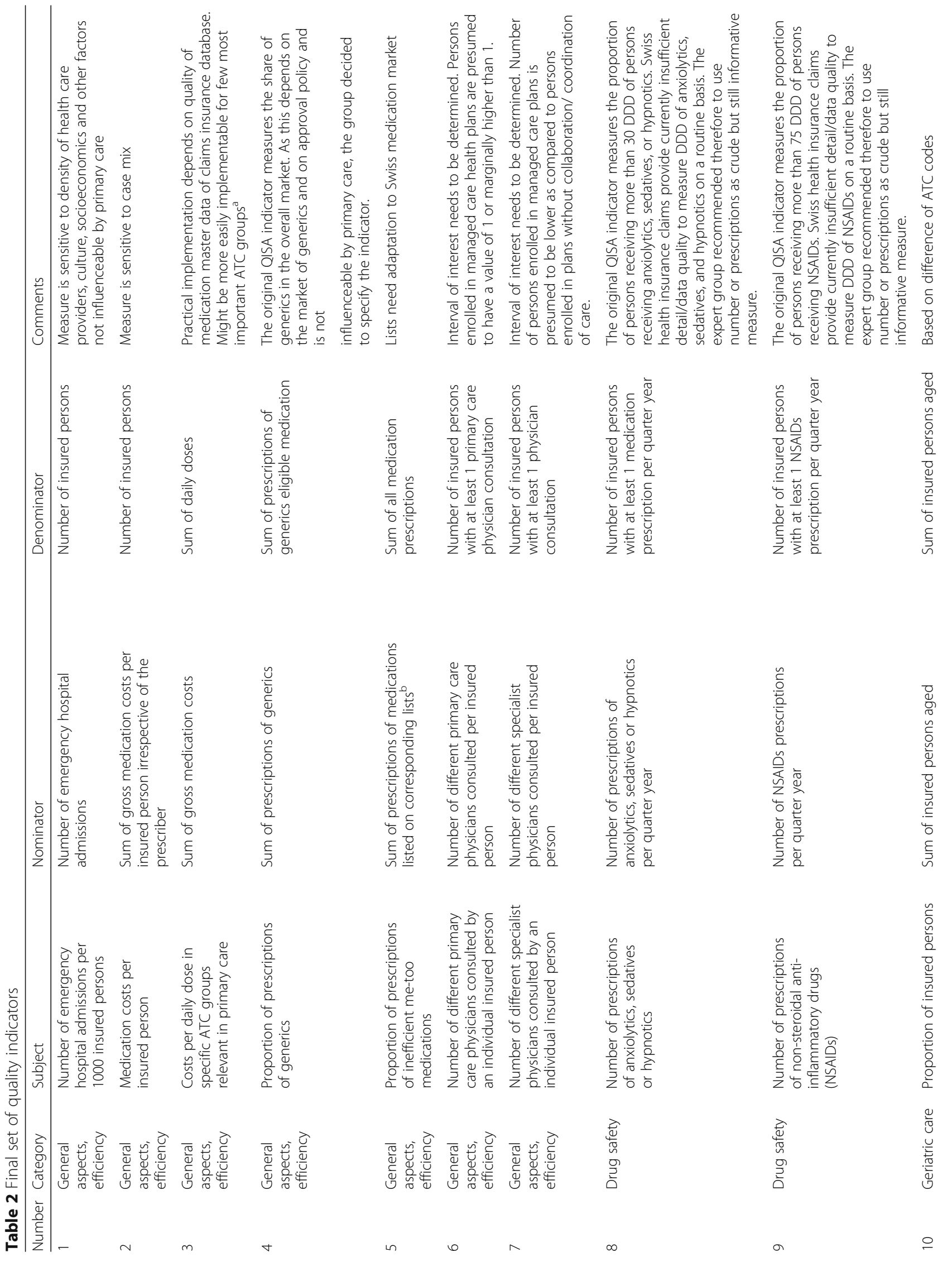




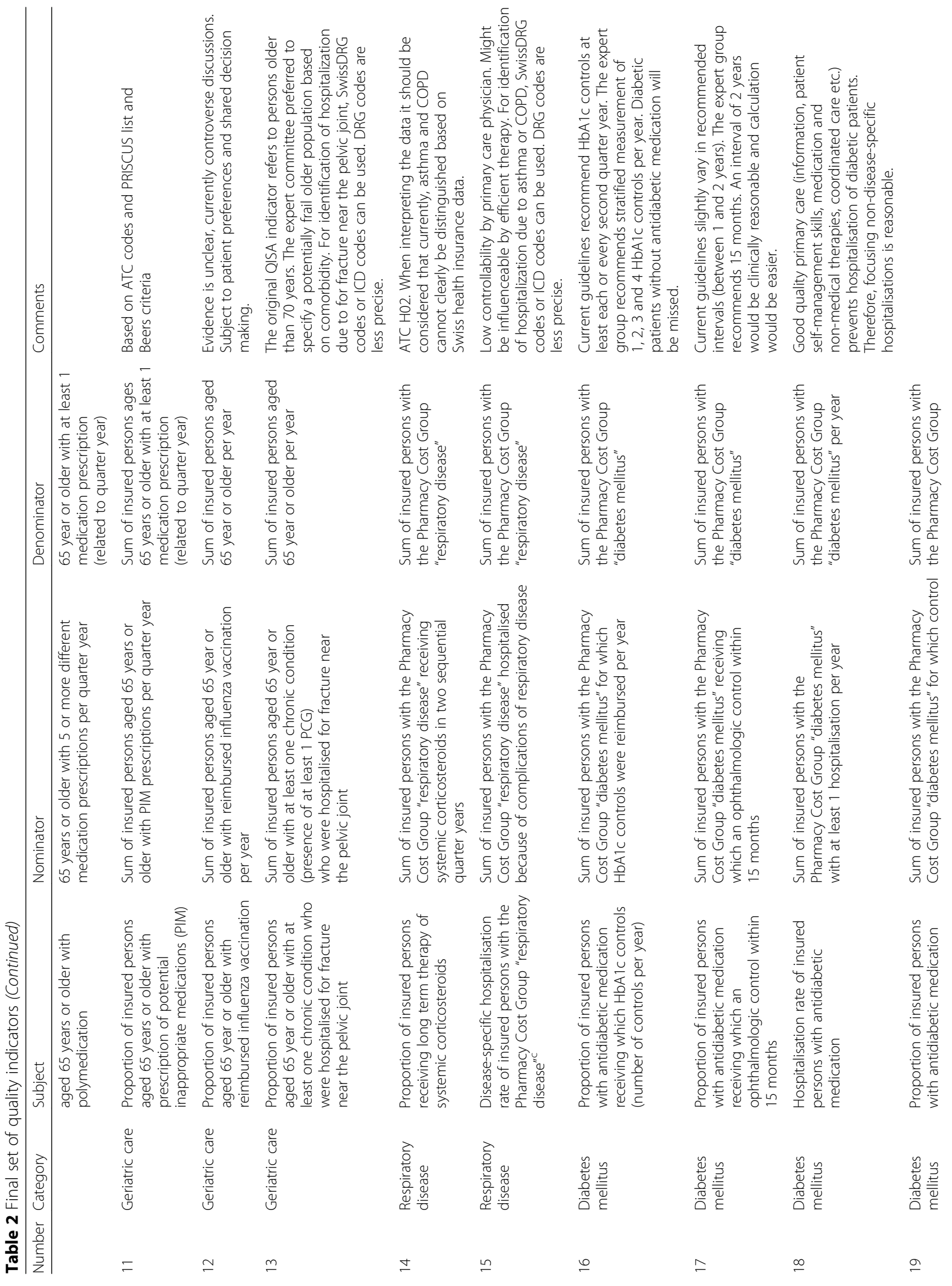




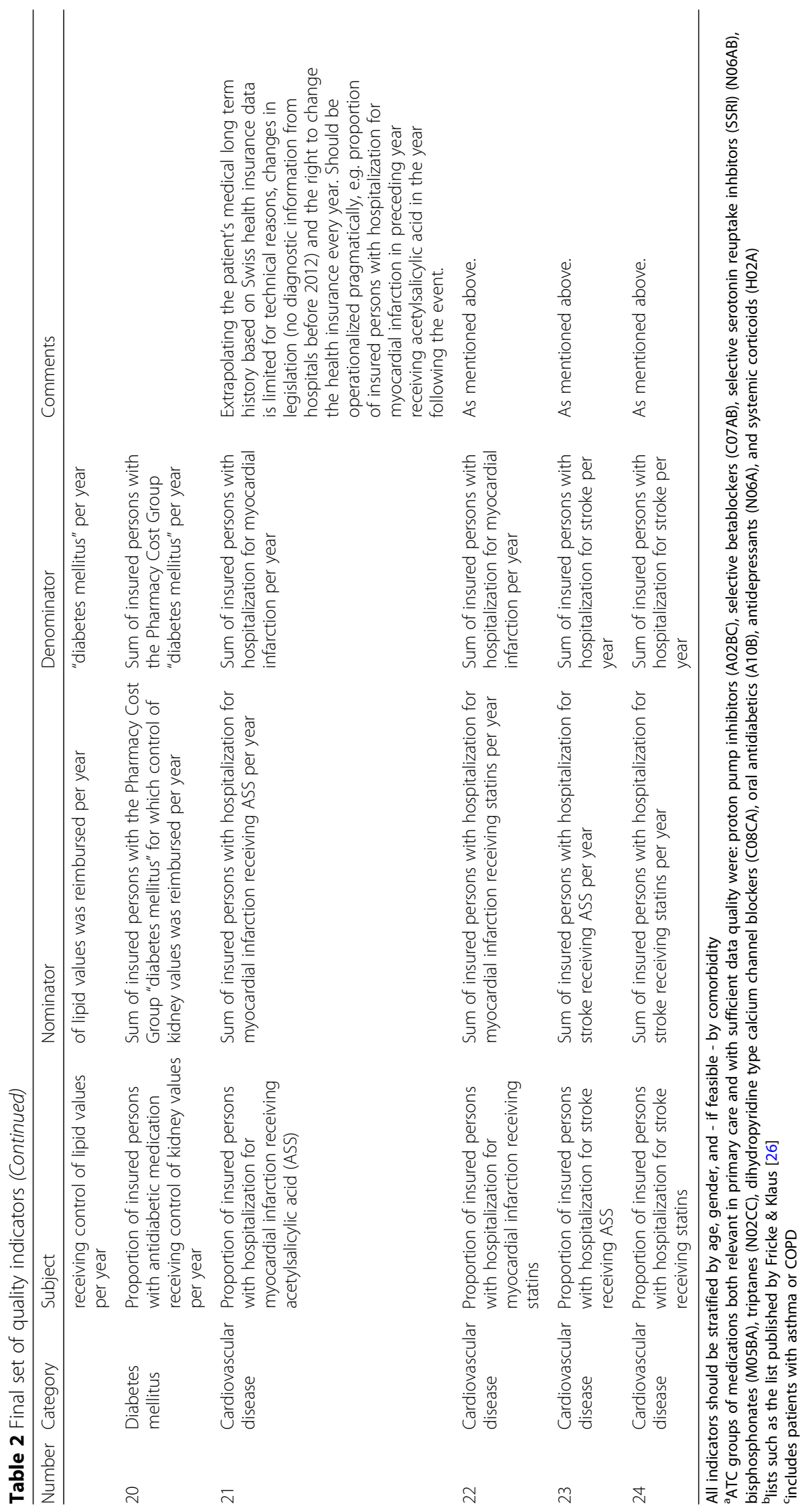


Therefore, SPAM complements the QI proposed by our group. Measuring quality both on the individual patient level and on a health system level might multiply insight in potential ways to improve quality of ambulatory primary care in Switzerland. The QI identified in the present study provide the opportunity to compare physician networks or even individual health service providers and therefore expand the operational conclusions that may be drawn from quality measurement.

Several limitations need to be considered. Firstly, we recruited a quasi-representative sample of experts for adapting international evidence to the Swiss healthcare setting. Therefore, the participants were not official representatives of stakeholder institutions but were selected based on their expertise related to primary care and/ or the Swiss health system. Secondly, the project was done from the perspective of Swiss mandatory basic health insurance. Therefore, services usually performed outside of the basic health insurance package were systematically not addressed in this project (e.g. services of supplementary insurance, over the counter medication, health-related life style, health promotion and prevention). However, the Swiss Swiss mandatory basic health insurance covers a very broad spectrum of all services needed for management of illness, accidents, and motherhood deemed to be effective, appropriate. and cost-efficient [35]. Thirdly, as our aim was to define QI for application on health insurance claims, we had to systematically exclude all aspects of quality that were not relevant for billing in the system of basic health insurance in Switzerland. Therefore, quality as reflected in satisfaction, communication, information, decision-making, or clinical results that impact the provision of health services at interest need to be addressed elsewhere. Fourthly, evidence-based QI can only be as good as the underlying evidence. Therefore, several aspects might be systematically under-or overrepresented depending on the presence or absence of evidence in certain clinical areas. Finally, data for feasibility testing came from a single health insurance, and results might differ when including data from other health insurances. However, the Helsana Group covers about 15\% of the Swiss population, and the representative nature of the data has repeatedly been shown before [36, 37].

The main strength of the project is the pragmatic methodology in response to current public debates on quality assurance in ambulatory care. The present study combined pre-existing evidence-appraisal from devoted institutions in Germany, internationally accepted methods for QI development, local expertise, and the pre-existing nature of health insurance claims data. Moreover, both the patient and the consumer perspective were represented in the expert group as considered the gold standard for the development of QI [38, 39].
The present study has implications for future research First, use of the proposed indicators needs to be evaluated. Specifically, future studies should assess if and how behaviour of physicians, frequency of unwarranted events such as hospitalisations, or costs change after introduction of P4P contracts. This is especially relevant since the evidence for P4P is not yet fully clarified, and international experiences are discussed controversially [40, 41].

Secondly, variance of quality across regions, settings, health insurance plans and patient groups need to be explored. Thirdly, an evidence-based instrument needs continuous update, evaluation, and continual adaptation [42]. For example, a current research project aims to develop QI for multimorbidity [43], and such indicators might be suitable for adaptation to the Swiss context and for future integration in the present set of QI.

In practice, QI constructed upon health insurance claims may provide the impetus to increase efforts for more quality in Swiss primary healthcare, to differentiate incentives for health care providers, and to increase quality competition across health care providers, health plans, and health insurances. The present QI may build the basis for the implementation of models that fit the Swiss needs.

\section{Conclusions}

Based on pre-existing foreign clinical practice guidelines and QI and on an informal expert consensus process we identified a broad set of QI for the measurement of quality of primary care in Switzerland that can be applied on nation-wide available health insurance claims data. Implementation of these indicators needs to be evaluated so that this set of QI can be continuously ameliorated and expanded. Local evidence related both to the level of quality of primary care and to the positive and negative effects of implementation of QI is urgently needed.

\section{Abbreviations}

ASS: Acetylsalicylic acid; ATC: Anatomical therapeutic chemical classification system; COPD: Chronic obstructive pulmonary disease; DDD: Defined daily dose; NSAID: Nonsteroidal anti-inflammatory drug; PCG: Pharmacy cost group; PIM: Potentially inappropriate medication; QI: Quality indicator

\section{Acknowledgements}

The methods of this project and preliminary results were presented at the symposia health services research of the Swiss Academy of Medical Sciences (SAMW), Bern 2015 and 2017, the annual meeting of the Swiss forum for integrated care (fmc), Bern 2016, the annual conference of the German association of primary care and family medicine (DEGAM), Frankfurt 2016, annual meeting of the European Association of Health Economics (EuHEA), Hamburg, 2016, and at the expert meeting of the EQUAM Foundation, Bern, 2017.

The Swiss Quality Indicator for Primary Care (SQIPRICA) Working Group members were:

PD Dr. med. Sima Djalali, Assistant physician, Spital Zollikerberg and Research Associate, Institute of Primary Care, University of Zürich, Zürich, Switzerland. Dr. med. Felix Huber, Medical director, MediX group practices Zürich, Zürich, Switzerland.

Dr. med. René Kühne, Department of Health Policy, Helsana Health Insurances, Zürich, Switzerland, 
Dr. med. Jan von Overbeck, Cantonal physician, Canton of Bern, Bern, Switzerland,

Prof. Dr. Dr. med. Thomas Rosemann, Director, Institute of Primary Care, University of Zurich, Switzerland,

Felix Schneuwly, Head of Public Affairs Swiss online comparative service Comparis, Zürich, Switzerland,

Prof. Dr. Martin Scherer, Director Department of General Practice/Primary Care, Hamburg University Medical School, Hamburg-Eppendorf, Hamburg, Germany.

Prof. Dr. med. Oliver Senn, Institute of Primary Care, University of Zurich, Zürich, Switzerland,

med. Pract. Daniel Tapernoux, medical advisor, Swiss Patient Organisation (SPO), Zürich, Switzerland.

\section{Funding}

Own resources of Helsana Health Insurances AG. The funder provided support in the form of salaries but did not have any additional role in the study design, data collection and analysis, decision to publish, or preparation of the manuscript.

\section{Availability of data and materials}

The datasets analysed during the current study are not publicly available because they are part of the confidential Helsana health insurance claims database. Additional information not included in the paper is available from the corresponding author on reasonable request.

\section{Authors' contributions}

All authors were involved in the study design. EB, OR, and MS conceived and designed the study. RR analysed the data. EB drafted the manuscript. OR, RR, MS, and the members of the Quality Indicator for Primary Care Working Group revised the manuscript. All authors participated in the interpretation of data, critically reviewed for important intellectual contents and gave the final approval of the version to be published.

\section{Ethics approval and consent to participate}

The analysis complied with the Swiss Federal Law on data protection. According to the national ethical and legal regulation, an ethical approval was not needed because the data were retrospective, pre-existing, and deidentified. Since data was anonymized, no consent of patients was required. Therefore, ethical approval and consent were waived.

\section{Consent for publication}

Not applicable.

\section{Competing interests}

$E B, R R$, and OR were affiliated with the Helsana Health Insurance Company at the time when the study was conducted. MS heads the guideline commission of the DEGAM (Ständige Leilinienkommission, SLK). EB is member of the SLK.

\section{Publisher's Note}

Springer Nature remains neutral with regard to jurisdictional claims in published maps and institutional affiliations.

\section{Author details}

${ }^{1}$ Department of Health Sciences, Helsana Group, P.O. Box, Zürich, Switzerland. ${ }^{2}$ Department of General Practice/Primary Care, University Medical Center Hamburg-Eppendorf, Hamburg, Germany. ${ }^{3}$ Division of General Practice, University Medical Centre Freiburg, Freiburg, Germany.

\section{Received: 21 February 2018 Accepted: 16 August 2018}

Published online: 27 September 2018

\section{References}

1. Senn N, Ebert ST, Cohidon C. Obsan Bulletin 11/2016: Die Hausarztmedizin in der Schweiz - Perspektiven. Analyse basierend auf den Indikatoren des Programms SPAM (Swiss Primary Care Active Monitoring). Swiss Health Observatory: Neuchâtel; 2016.

2. Schweizer Forum für Intergrierte Versorgung fmc: Neue Versorgungsmodelle für die medizinische Grundversorgung. Bericht der Arbeitsgruppe "Neue Versorgungsmodelle für die medizinische
Grundversorgung" von GDK und BAG. 2012. https://www.fmh.ch/files/ pdf13/versorgungsmodelle_d.pdf. Accessed 10 Feb 2018.

3. Chmiel C, Bhend H, Senn O, Zoller M, Rosemann T. The FIRE project: a milestone for research in primary care in Switzerland. Swiss Med Wkly. 2011; 140:w13142.

4. EQUAM Stiftung: Unser Angebot. 2018. https://www.equam.ch/de/. Accessed 10 Feb 2018.

5. Mehrfacharzt: Die Zertifizierung als "MehrFachArzt" oder "MehrFachÄrztin". 2018. http://www.mehrfacharzt.ch/fuer-hausaerzte/zertifizierung/. Accessed 10 Feb 2018.

6. QBM-Stiftung: QBM - von Ärzten für Ärzte. 2018. https://www.qbm-stiftung. ch/qbm.html. Accessed 10 Feb 2018.

7. Berchtold P, Schmitz C, Maier J. Obsan Report 51: Guidelines in Schweizer Ärztenetzen. Entwicklung und Bedeutung. Swiss Health Observatory: Neuchâtel; 2012.

8. Meyer K. Gesundheit in der Schweiz - Nationaler Gesundheitsbericht 2008. Swiss Health Observatory: Neuchâtel; 2010.

9. Swiss Federal Office of Public Health: Quality Assurance. 2018. https://www. bag.admin.ch/bag/en/home/themen/versicherungen/krankenversicherung/ krankenversicherung-qualitaetssicherung.html. Accessed 10 Feb 2018.

10. Institute of Medicine. To err is human: building a safer health system. Washington, DC: National Academy Press; 1999.

11. Lester H, Roland M. Performance measurement in primary care. In: Smith P, Mossialos E, Papanicolas I, Leatherman S, editors. Performance Measurement for Health System Improvement. Cambridge: Cambridge University Press; 2009.

12. Campbell SM, Kontopantelis E, Hannon K, Burke M, Barber A, Lester HE. Framework and indicator testing protocol for developing and piloting quality indicators for the UK quality and outcomes framework. BMC Fam Pract. 2011;12:85.

13. Swiss Federal Office of Public Health: Comparisons and Analyses of Health Systems. 2018. https://www.bag.admin.ch/bag/en/home/themen/ internationale-beziehungen/internationalegesundheitsthemen/ comparaisons-analyses-systemes-sante.html. Accessed 19 April 2018.

14. Swiss Federal Office of Public Health: Ein Netzwerk für mehr Qualität in der Gesundheitsversorgung. 2018. https://www.bag.admin.ch/bag/de/home/ themen/versicherungen/krankenversicherung/krankenversicherungrevisionsprojekte/netzwerk-qualitaet-gesundheitsversorgung.html. Accessed 19 April 2018

15. Limb M. OECD finds some countries are too restrictive about sharing personal data. BMJ. 2013;346:f2116. https://doi.org/10.1136/bmj.f2116.

16. Swiss Academy of Medical Sciences. Stärkung der Versorgungsforschung in der Schweiz. Swiss Academies Reports 2014; 9(1). https://www.samw.ch/de/ Publikationen/Positionspapiere.html. Accessed 19 April 2018.

17. Cohidon C, Cornuz J, Senn N. Primary care in Switzerland: evolution of physicians' profile and activities in twenty years (1993-2012). BMC Fam Pract. 2015;16:107.

18. Tandjung R, Hanhart A, Bärtschi F, Keller R, Steinhauer A, Rosemann T, Senn $O$. Referral rates in Swiss primary care with a special emphasis on reasons for encounter. Swiss Med Wkly. 2015;145:w14244.

19. Swiss Federal Office of Public Health: Statistik der obligatorischen Krankenversicherung. 2018. https://www.bag.admin.ch/bag/de/home/ service/zahlen-fakten/statistiken-zur-krankenversicherung/statistik-derobligatorischen-krankenversicherung.html. Accessed 10 Feb 2018

20. Hostettler S, Kraft E. FMH-Ärztestatistik 201636175 berufstätige Ärztinnen und Ärzte. Schweiz Ärzteztg. 2017:98(13):394-400.

21. The Commonwealth Fund: The Swiss Health Care System. 2016. https:// international.commonwealthfund.org/countries/switzerland/ Accessed 01 Aug 2018.

22. Programm für Nationale VersorgungsLeitlinien von BÄK, KBV und AWMF: Qualitätsindikatoren- Manual für Autoren. 2009. http://www.aezq.de/mdb/ edocs/pdf/schriftenreihe/schriftenreihe36.pdf. Accessed 10 Feb 2018.

23. AQUA Institut: Allgemeine Methoden. 2015. https://www.aquainstitut.de/ fileadmin/aqua_de/Projekte/248_Methodenpapier/Methodenpapier_4.0.pdf. Accessed 10 Feb 2018.

24. German College of General Practitioners and Family Physicians: S3-Leitlinien der DEGAM - der Zehnstufenplan. 2009. http://www.degam.de/id-10-stufenplan.html. Accessed 10 Feb 2018.

25. Huber CA, Szucs TD, Rapold R, Reich O. Identifying patients with chronic conditions using pharmacy data in Switzerland: an updated mapping approach to the classification of medications. BMC Public Health. 2013;13: 1030. 
26. Schwabe U, Paffrath D. Arzneiverordnungs-Report 2016. Berlin: Springer; 2016.

27. Holt S, Schmiedl S, Thurmann PA. Potentially inappropriate medications in the elderly: the PRISCUS list. Dtsch Arztebl Int. 2010;107(31-32):543-51.

28. American Geriatrics Society. Beers Criteria Update Expert Panel. American Geriatrics Society updated Beers Criteria for potentially inappropriate medication use in older adults. J Am Geriatr Soc. 2012;60(4):616-31.

29. World Health Organization: ATC/DDD Index. 2018. http://www.whocc.no/ atc_ddd_index/. Accessed 10 Feb 2018.

30. Huber CA, Brändle M, Rapold R, Reich O, Rosemann T. A set of four simple performance measures reflecting adherence to guidelines predicts hospitalization: a claims-based cohort study of patients with diabetes. Patient Prefer Adherence. 2016;10:223-31.

31. Huber CA, Rapold R, Brüngger B, Reich O, Rosemann T. One-year adherence to oral antihyperglycemic medication and risk prediction of patient outcomes for adults with diabetes mellitus: An observational study. Medicine (Baltimore). 2016;95(26):e3994.

32. Huber CA, Reich O, Früh M, Rosemann T. Effects of Integrated Care on Disease-Related Hospitalisation and Healthcare Costs in Patients with Diabetes, Cardiovascular Diseases and Respiratory Illnesses: A PropensityMatched Cohort Study in Switzerland. Int I Integr Care. 2016;16(1):11.

33. Schweizer Forum für Intergrierte Versorgung fmc: Presentation of Schmutz DH at the Swiss national Symposium of Integrated Care2016, Bern, Switzerland. Performance-basierte Vergütung: Auch im Gesundheitswesen? 2016. https://fmc.ch/_Resources/Persistent/ 44cf7867c819aec35e6beac171ce7640ccf60b68/2016_Keynote_4_Daniel_H_ Schmutz.pdf. Accessed 10 Feb 2018.

34. Ebert ST, Pittet V, Cornuz J, Senn N. Development of a monitoring instrument to assess the performance of the Swiss primary care system. BMC Health Serv Res. 17(1):789.

35. Herzlinger RE, Parsa-Parsi R. Consumer-driven health care: lessons from Switzerland. JAMA. 2004;292(10):1213-20. https://doi.org/10.1001/jama.292. 10.1213, 292/10/1213.

36. Helsana Group: Helsana Drug Report 2017. 2017. https://www.helsana.ch/ en/helsanagroup/about-our-company/health-sciences/drug-report. Accessed 10 Feb 2018.

37. Helsana Group: Helsana Report Ausgabenentwicklung in der Gesundheitsversorgung. 2016. https://www.helsana.ch/de/helsana-gruppe/ unternehmen/gesundheitswissenschaften/ausgabenreport. Accessed 10 Feb 2018.

38. Pohontsch NJ, Herzberg H, Joos S, Welti F, Scherer M, Blozik E. The professional perspective on patient involvement in the development of quality indicators: a qualitative analysis using the example of chronic heart failure in the German health care setting. Patient Prefer Adherence. 2015;9: $151-9$.

39. Kötter T, Schaefer FA, Scherer M, Blozik E. Involving patients in quality indicator development - a systematic review. Patient Prefer Adherence. 2013;7:259-68

40. Mendelson A, Kondo K, Damberg C, Low A, Motúapuaka M, Freeman M, O'Neil M, Relevo R, Kansagara D. The Effects of Pay-for-Performance Programs on Health, Health Care Use, and Processes of Care: A Systematic Review. Ann Intern Med. 2017;166(5):341-53.

41. Ryan AM, Krinsky S, Kontopantelis E, Doran T. Long-term evidence for the effect of payfor-performance in primary care on mortality in the UK: a population study. Lancet. 2016;388(10041):268-74.

42. Kötter T, Blozik E, Scherer M. Methods for the guideline-based development of quality indicators--a systematic review. Implement Sci. 2012;7:21.

43. Blozik E, Lühmann D, Scherer M. Entwicklung und Validierung von Qualitätsindikatoren für Multimorbidität (Multiqual). In: Amelung VE, Eble S, Hildebrandt H, Knieps F, Lägel R, Ozegowski S, Schlenker R-U, Sjuts R, editors. Innovationsfonds, Impulse für das deutsche Gesundheitswesen. Berlin: Medizinisch Wissenschaftliche Verlagsgesellschaft; 2017.

Ready to submit your research? Choose BMC and benefit from:

- fast, convenient online submission

- thorough peer review by experienced researchers in your field

- rapid publication on acceptance

- support for research data, including large and complex data types

- gold Open Access which fosters wider collaboration and increased citations

- maximum visibility for your research: over $100 \mathrm{M}$ website views per year

At BMC, research is always in progress.

Learn more biomedcentral.com/submissions 